Original Research Paper

\title{
Parenting, Adolescents' Future Orientation, and Adolescents' Efficient Financial Behaviors in Young Adulthood
}

\author{
${ }^{1}$ Sun-A Lee and ${ }^{2}$ Jeong Jin Yu \\ ${ }^{I}$ Department of Sociology, Anthropology and Child and Family Studies, University of Louisiana, Lafayette, USA \\ ${ }^{2}$ Department of Psychology, Umea University, Umea, Sweden
}

\author{
Article history \\ Received: 13-07-2017 \\ Revised: 20-08-2017 \\ Accepted: 13-10-2017 \\ Corresponding Author: \\ Sun-A Lee \\ Department of Sociology, \\ Anthropology, Child and \\ Family Studies, University of \\ Louisiana, Lafayette, USA \\ Email: slee@louisiana.edu
}

\begin{abstract}
The current study examined how parenting behaviors during adolescence would be related to adolescent children's financial efficiency in early adulthood. We also examined if there was a possible mediator of this link. Data for this investigation $(\mathrm{N}=1385)$ were drawn from the high school and young adult in the Michigan Study of Adolescent Life Transitions, 22-year 9-wave investigation. It was found that parenting behaviors including parental advice for children's future and parents' involvement in children's activities in middle adolescence $\left(10^{\text {th }}\right.$ grade $)$ predicted children's future oriented attitudes in late adolescence $\left(12^{\text {th }}\right.$ grade), which in turn predicted efficient financial behaviors in their early adulthood (21 years old and 24 years old). Contribution, limitations and implication of the study were discussed.
\end{abstract}

Keywords: Parenting Behaviors, Adolescents' Future Orientation, Financial Efficiency in Young Adulthood

\section{Introduction}

In recent decades, individuals' inefficient and irresponsible financial behaviors, such as too much credit card debt or impulsive consumption, have been increasing (Baek and Hong, 2004; Norvilitis, 2014; Stones and Maury, 2006; Webley and Nyhus, 2006). Studies show that individual financial difficulties are related to increased stress levels and decreased levels of psychological well-being (Dew, 2008; Roberts and Jones, 2001; Shen and Sam, 2014) and can even lead to suicide (Holub, 2002). Considering the current global economic situation, young adult's efficient financial behaviors may be critical for psychological well-being possibly more than ever before.

Scholars have attempted to identify characteristics of those individuals with inefficient financial behaviors. However, most studies (e.g., Bradford, 2003; Olsen and Cox, 2001) have examined individual demographic information, such as individual and parental income and education levels, ethnicity, or gender, rather than examining what kind of family processes these individuals experienced within families, such as parentchild relationship quality and how these processes are related to individual financial behaviors. Parental influence has been addressed in some studies for understanding children's financial behaviors; however, those studies mostly focus on intergenerational transmission of economic behaviors by comparing parents' and children's financial behaviors (e.g., Cotte and Wood, 2004). In other words, researchers just assume that children model, learn and internalize their parents' economic behaviors without examining the process by which parents influence their children.

\section{Do Parenting Behaviors Make a Difference in Children's Financial Behaviors?}

Parenting behaviors or parent-child relationship quality have been found to be crucial for children's adjustment in many ways, such as high self-esteem, positive self-concept, self-confidence, better academic achievement, less depression, less anti-social behaviors and healthier relationship skills (e.g., Aquilino, 2006; Carlson, 2006; Reczek et al., 2017; Stafford et al., 2016). In addition, some studies found the link between poor parent-child relationships and negative financial attitudes and/or behaviors, such as materialism and conspicuous consumption; poor parent-child relationships (e.g., less attached parent-child relationships or less nurturing mothers) are more likely to be related to materialism in children (Jiang et al., 2015; Kasser et al., 1995) and conspicuous consumption (Gudmunson and Beutler, 2012), whereas adolescents with higher satisfaction in the relationships 
with their parents were less likely to hold materialism (Bae, 2016; Flouri, 1999). In addition, children whose parents are authoritative are more likely to have money conscientiousness and save money (Ashby et al., 2011; Kim et al., 2011; Nyhus and Webley, 2007).

There are studies on the impact of parenting behaviors on children's financial behaviors; however, they are limited to: (1) simply examining a concurrent association between parental economic socialization and adolescents' economic behavior (e.g., Clarke et al., 2005; Pinto et al., 2005; Serido et al., 2010); (2) using retrospective data (e.g., Grinstein-Weiss et al., 2012; Webley and Nyhus, 2006) or using cross-sectional data (e.g., Bernheim et al., 2001) for the relationships between parental economic socialization in childhood and adult offspring's current financial behaviors; (3) examining parental teaching money-saving value only rather than financial advice for the future (e.g., Bernheim et al., 2001); and (4) general communication style (sociooriented vs. concept-oriented) rather than parental advice for the future and its effect on children's consuming behavior (e.g., Caruna and Vassallo, 2003; Moschis, 1985). In addition, it is hard to find the conceptual framework that can explain or suggest how parenting behaviors can influence children's financial behaviors. Hence, the current study examines whether and how parenting behaviors during adolescence are related to children's financial behaviors later in young adulthood using longitudinal data. In addition, the study suggests the conceptual framework explaining the link between parenting behaviors and children's financial behaviors.

Future Orientation of Adolescents as a Mediator between Parenting Behaviors and Financial Efficiency of Adolescents in Young Adulthood

How can early good parenting behaviors or parentchild relationships make a difference in children's financial behaviors in later life? Can this be understood that children's financial behaviors are just one of the psychological or behavioral outcomes of children that parenting behaviors affect, such as depression and academic achievement? Or is there a possible mechanism involved with the association of parenting behaviors and children's financial behaviors following? In other words, what mechanisms are involved with the association of parenting behaviors or parent-child relationship quality and children's financial behaviors? Our conceptual framework for understanding this focuses on children's future orientation as a mediator between parenting behaviors and children's financial behaviors (Fig. 1).

\section{Future Orientation and Financial Efficiency}

As shown in Fig. 1, the current study will examine adolescents' future orientation as a mediator between parenting behaviors and financial efficiency of children in young adulthood. Future orientation generally refers to how people value, hope, expect and concern for their own futures and involves three major psychological processes-motivation, planning and evaluation (Nurmi, 1991). Also, future orientation implies how much individuals believe their current behaviors and decisions impact their future and plan for their future (Liu et al., 2014). Developmentally, adolescents are able to envision their future, which is referred to as future orientation (Arnett, 2000). Future-oriented people are less concerned with the here and now and more focused on upcoming events. To live in the moment is antithetical to their way of thinking (Nyhus and Webley, 2013). Research shows that adolescents with a negative future orientation are more likely to engage in risk-taking behavior with little regard to the consequences. Conversely, adolescents with a positive future orientation are less likely to take unnecessary risks or engage in risky behavior such as substance abuse or sexual risk taking (e.g., Robbins and Bryan, 2004). They are also more likely to be higher achievers academically (e.g., Nurmi, 1991).

However, adolescents' future oriented attitudes are not just a temporary attitude for the current situation, but a long-term involved action for their goal searching, planning to achieve them and evaluating their actions for the future. Since they are future oriented with their goals, it would not be surprising that adolescents with positive and healthy future-oriented attitudes show healthy behaviors and better psychosocial adjustment, including better financial behaviors. Given that managing their finances is a big part of their lives, their careful, planned and efficient financial behaviors in contemporary and future life should be related to their future oriented attitudes. Indeed, Webley and Nyhus (2001) found that adults' future oriented attitudes are positively related to economic behaviors, such as less financial debt. Also, they examined whether individual's future orientation is related to the pattern of spending money and found that future orientation is positively related to saving money and spending money timely (Webley and Nyhus, 2006). More recently, they examined 597 adolescents who aged 14-16 years and their parents in Norway. They found that adolescents' future oriented perspectives were related to better financial behaviors, such as controlled spending (Nyhus and Webley, 2013). However, their studies are by the reliance on retrospective and concurrent data regarding future orientation of adolescents and their financial behaviors.

\section{Parenting Behaviors and Future Orientation}

As parenting behaviors affect many aspects of children's psychosocial outcomes (e.g., depression, selfesteem), children's future orientation can be affected by parenting behaviors. There are some empirical supports 
for the link between positive relationships with parents and children's positive future orientation (e.g., Mauro and Harris, 2000; Reitman and Gross, 1997). For example, it has been documented that a variety of protective parenting, such as parental support (Dubow et al., 2001), family discussions (Nurmi and Pulliainen, 1991), parental involvement (Pulkkinen, 1990) and parental authoritative parenting and openness (Kracke, 1997), influence children's future orientation. In addition, Seginer et al. (2004) examined the link between parenting style and high school students' future orientated attitudes. They found that autonomousaccepting parenting is associated with adolescent future orientation. However, it is hard to find the conceptual framework why and how those parenting behaviors, such as 'nurturing,' 'supportive,' and 'responsive' parenting, are related to children's future orientation. How can those 'good' parenting behaviors affect children's future oriented attitudes? It is worthwhile to note the role of parents to children during adolescence.

In developmental perspectives, adolescence is regarded as a period during which individuals achieve their identity through exploring themselves. Exploring their identity can be associated with thinking about and planning for the future (Erikson, 1959; 1968; Malmberg et al., 2005). It is widely reported that when adolescents think about and plan for the future (Tucker et al., 2001), they are likely to seek advice regarding future plans (Barber, 1994; Barber and Eccles, 1992) and frequently turn to their parents for advice (Steinberg and Silk, 2002). Each family has its own rules, attitudes, values and expectations that children learn and adapt to their own life. Parents provide a guideline helping adolescents create pictures about their own future (Jambori and Sallay, 2003). Hence, when adolescents lean on their parents for advice, parents play an important role during the process when adolescents try to establish their own sense of future, such as career plan or education plan. Thus, one of the 'good' parenting behaviors should be one fitting the needs of children based on their developmental stage, such as their current interest and skills (Wood and Middleton, 1975).

Hence, open-communication and advice about future concerns, which is especially related to career and finance matters, from parents during adolescence are likely to be 'needed' parenting behaviors for adolescents who are supposed to plan for their future with their seeking of identity. Also, during those interactions between parents and children, adolescents can develop future oriented attitudes which are involved with setting goals with motivation, planning and evaluating for present and future. However, it is hard to find a study that conceptually explains why and how parenting behaviors impact adolescent children's future orientation.

\section{The Current Study}

The current study aimed to examine how earlier parenting behaviors, adolescents' future orientation and adolescents' efficient financial behaviors later in young adulthood would be related to one another, using data from a prospective and longitudinal study. Parenting behaviors are measured based on parental advice for adolescents' future career and earning money and on parental involvement and caring about adolescents' activities. Since occupation (e.g., Goldberg et al., 1985) and education (e.g., Payne, 1988) have been found to be the most frequently reported content for adolescents' goals for the future, parental advice for adolescent children's job plans for the future was examined. Adolescents' future orientation is measured regarding their career aspirations and career identity and their financial behaviors are measured based on how efficient they perceive they are in managing money in young adulthood. It is worthy to note that our samples are composed of college as well as non-college youth. Many studies on young adults' financial behaviors (e.g., Roberts and Jones, 2001) used a convenient sample from a university setting; hence, this sample can enhance the representativeness of youth.

The specific questions are, as seen in Fig. 1, as follows: (1) Does parenting behaviors measured by parental advice for the future plan during adolescence and involved parenting predict later financial efficiency in young adulthood? (2) Does adolescent future orientation mediate the link between parenting behaviors and financial efficiency in young adulthood? When examining those research questions, adolescent's psychosocial adjustment was also taken into account because adolescent's psychosocial adjustment is a crucial predictor for their behaviors in later life, including financial behaviors (Lee et al., 2000).

\section{Method}

\section{Participants}

Data were drawn from the Michigan Study of Adolescent Life Transitions (MSALT). A 22-year 9wave investigation, MSALT began in 1983 when the participants were the sixth grade. This study was designed to investigate normative and non-normative transitions during adolescence. Analyses for this study are based on Wave 5 data collected in 1988 when participants were in grade 10 , Wave 6 data collected in 1990 when participants were in grade 12, Wave 7 data collected in 1992-1993 via mailed surveys, two to three years after the majority of the sample had graduated from high school (21 years old) and Wave 8 data collected in 1996 via mailed surveys when the majority of the sample were 24 years old (Fig. 1). 


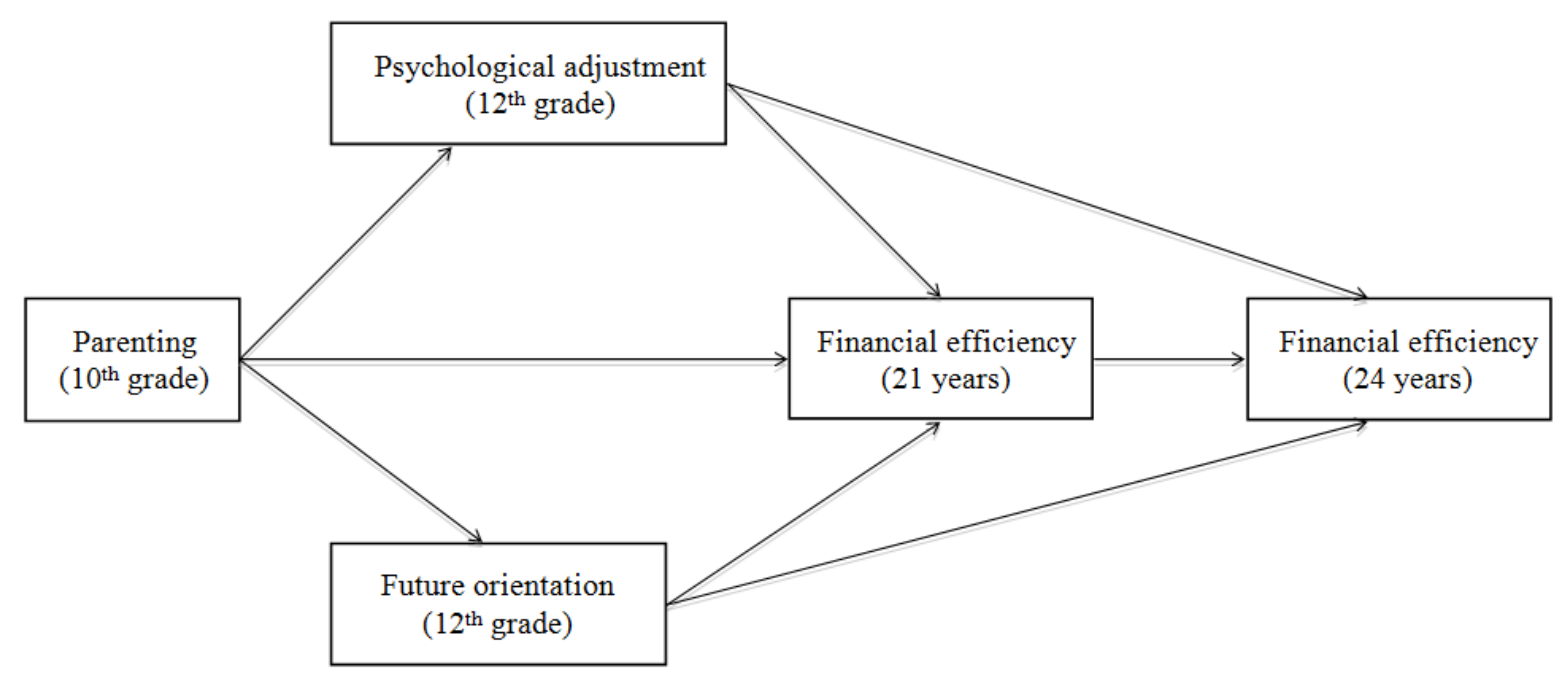

Fig. 1. Conceptual model representing predictors of financial efficiency in early adulthood

The sample was from only always-married families at Wave $5\left(10^{\text {th }}\right.$ grade $)$ and the final sample consisted of 1385 youths $(44.7 \%$ males). The current study included children from always-married families only in order to exclude possible third variables influencing children's psychosocial adjustment and financial behaviors (e.g., experiencing parental divorce and/or remarriage of parents). The number of intact families remained relatively stable over the waves (i.e., 1370 intact families at Wave 7). The participants were from ten predominantly white middle and lower class school districts in Southeastern Michigan. Most of the sample (94.1\%) was white/Caucasian. Regarding parental educational level, $21.3 / 17.2 \%$ of the fathers/mothers had earned a four-year college degree or more, $13.7 / 10.8 \%$ of the fathers/mothers had completed some years of college or vocational/technical school and $25.3 / 32.3 \%$ of fathers/mothers had a high school degree or less. Approximately $40 \%$ of both fathers' and mothers' educational level was not reported. Average annual family income at Wave 6 (i.e., 1990) was between 40,000 to $\$ 60,000$. At the age of 21 years (i.e., Wave 7), $17.2 \%$ attend college and $81.4 \%$ did not. At the age of 21 years, $80.8 \%$ were single, but at the age of 24 years (i.e., Wave 8), $78.2 \%$ were married. At the age of 21 years, $52.7 \%$ held full-time jobs and at the age of 24 years, $69.1 \%$ had full time jobs.

\section{Measures}

At Waves 5 and 6, students were given 90 minutes to fill out questionnaires in their school cafeterias while research staff members were present to answer questions. Questionnaires and postage-paid return envelopes were mailed to students who had participated in previous waves of data collection but were absent on the day of the survey. At Waves 7 and 8 , surveys and postage-paid return envelopes were mailed to respondents.

\section{Parenting Behaviors}

At Wave $5\left(10^{\text {th }}\right.$ grade), adolescents were asked to answer the questions about the degree of parental involvement and parental advice from fathers and mothers. Questions for parents' involvement consisted of four items ("My parents praise me for doing well," "My mother takes an interest in my activities," "My "My father takes an interest in my activities," and "My parents encourage me to do my best on everything I do") scaled from $1=$ "never" to $7=$ "a lot." (alpha =0.76). Questions for parental advice consisted of six items ("My father and I talk about my job plans," "My father and I talk about my future plans," "My mother and I talk about my job plans," "My mother and I talk about my future plans," "My parents and I talk a lot about future jobs that I might have," and "My parents and I talk about how important it is to be able to earn enough to support myself and my family") scaled from $1=$ "strongly disagree" to $7=$ "strongly agree." $($ alpha $=0.81)$.

\section{Psychosocial Adjustment}

At Wave $6\left(12^{\text {th }}\right.$ grade), adolescents were asked to answer the question about self-esteem and depression symptoms. Questions for self-esteem consisted of three items ("Feel good about yourself," "Feel satisfied with yourself the way you are," and "Feel sure of who you are [what kind of person you are]") scaled from $1=$ "never" to $7=$ "daily." (alpha $=0.81)$. Questions for depression consisted of four items ("Lose your appetite or eat a lot when you get upset," "Feel unhappy, sad, or depressed," "Feel lonely," and "Feel that difficulties are piling up so high you can't overcome them") scaled from $1=$ "never" to $7=$ "daily." (alpha $=0.73)$. 


\section{Future Orientation}

At Wave $6\left(12^{\text {th }}\right.$ grade $)$, adolescents answered to the question about their future attitudes toward job identification and occupational aspiration. Questions for job identification consisted of four questions ("How sure are you that this is the kind of job you would like?" "How much have you thought about this choice?" "How likely is it that you will be successful in this kind of job?" and "How likely do you think it is that you will have this kind of job?") rated from $1=$ "not at all" to $7=$ "very much." (alpha = 0.82). Questions for occupation aspiration consisted of five questions ("You will have a job you enjoy doing," "You will be a success in your line of work," "You will have a job that pays well," "You will be laid off from your job," and "You will have difficulty supporting your family financially") scaled from 1 = "not at all" to 7 = "very much" $($ alpha $=0.76)$.

\section{Financial Efficiency}

At Wave 7 and 8 (age 21 and 24), young adults were asked the questions for their perceptions of efficient financial behaviors. The questions consisted of four questions ("Earning your own living," "Paying bills," "Using your credit cards" and "Managing money") for each wave, which rated from $1=$ "not at all well" to $7=$ "extremely well." (alpha $=0.76$ for Wave 7 and 0.72 for Wave 8 ).

\section{Results}

\section{Descriptive Statistics}

Descriptive statistics for and correlations among the study variables are presented in Table 1 . All correlations were in the expected directions and provide preliminary support for the expected relationships in the study.

\section{Path Analysis}

The proposed model was tested by Structural Equation Modeling (SEM) using AMOS Version 5.0 (Arbuckle, 2003). There was a considerable amount of missing data, ranging from $22.4 \%$ to $44.7 \%$ across the variables; thus the Full Information Maximum Likelihood (FIML) procedure was utilized. AMOS allows the users to estimate the model in the presence of missing data using the FIML procedure. This approach is less biased than more traditional methods (i.e., list-wise deletion, pairwise deletion and mean substitution) and increases the statistical power to analyze the data set (Enders and Bandalos, 2001; Tomarken and Waller, 2005). It was also demonstrated that a data set even with $50 \%$ of missing information using FIML still provides fairly accurate parameter estimates and the standard errors in SEM (Choi et al., 2005). This path analysis allowed us to analyze the dynamics of variables in a longitudinal way. Several demographic variables were included as controls in the initial models in order to see whether these demographic variables should be controlled for in the structural analysis. These variables included parental educational level, household annual income and employment status, marital status and educational level of the participants. However, none of the models provided an acceptable fit to the data, except for a model containing a path from college enrollment at Wave 7 as a control variable to financial efficiency at Wave 7, $\chi^{2}(20)=107.1$, Comparative Fix Index $(\mathrm{CFI})=$ 0.927, Root Mean Square Error Of Approximation $($ RMSEA $)=0.042(\mathrm{CI}, 0.034-0.050)$. However, a model without any covariates achieved a much better fit to the data than the above model, $\chi^{2}(17)=82.1, \mathrm{CFI}=0.944$, RMSEA $=0.039$ (CI, 0.031-0.048) (Fig. 2.)

The Dynamics of Parenting Behaviors, Future Orientation in Adolescence and Efficient Financial Behaviors in Young Adulthood

As seen in Fig. 2, it was found that parenting behaviors measured by parental advice and parental involvement predicted adolescent's occupational aspiration $(\beta=0.50, \quad p<0.001)$ and adolescent's adjustment $(\beta=0.45, p<0.001)$ two years later. The more involved parents are and the more future advice parents give to their adolescent children, the higher adolescents have occupational aspirations and the better they adjusted two years later. However, parenting behaviors in adolescence was not directly related to efficient financial behaviors in young adulthood. Adolescents' adjustment significantly predicted their financial efficiency at age $21(\beta=$ $0.20, p<0.001)$. Adolescent's occupational aspiration in $12^{\text {th }}$ grade significantly predicted their financial efficiency when they were 24 years old $(\beta=0.16, p<$ $0.001)$. In addition, young adults' financial efficiency at age 21 predicted their efficient financial behaviors at age $24(\beta=0.39, p<0.001)$.

To assess our mediation, we used the bias corrected bootstrap method with 5,000 random resamples from the original dataset because this technique provides accurate Confidence Interval (CI) estimation (Cheung and Lau, 2008; Preacher and Hayes, 2008). A 95\% CI not containing the value of zero indicates statistical significance of mediation. Bootstrap results revealed that adolescent's adjustment and occupational aspiration significantly mediated the associations between parenting behaviors and their financial efficiency at age 21 or 24 , respectively. In other words, positive parenting behaviors predicted their adolescent children's better psychosocial adjustment and occupational aspirations, which in turn predicted their financial efficiency in young adulthood. 


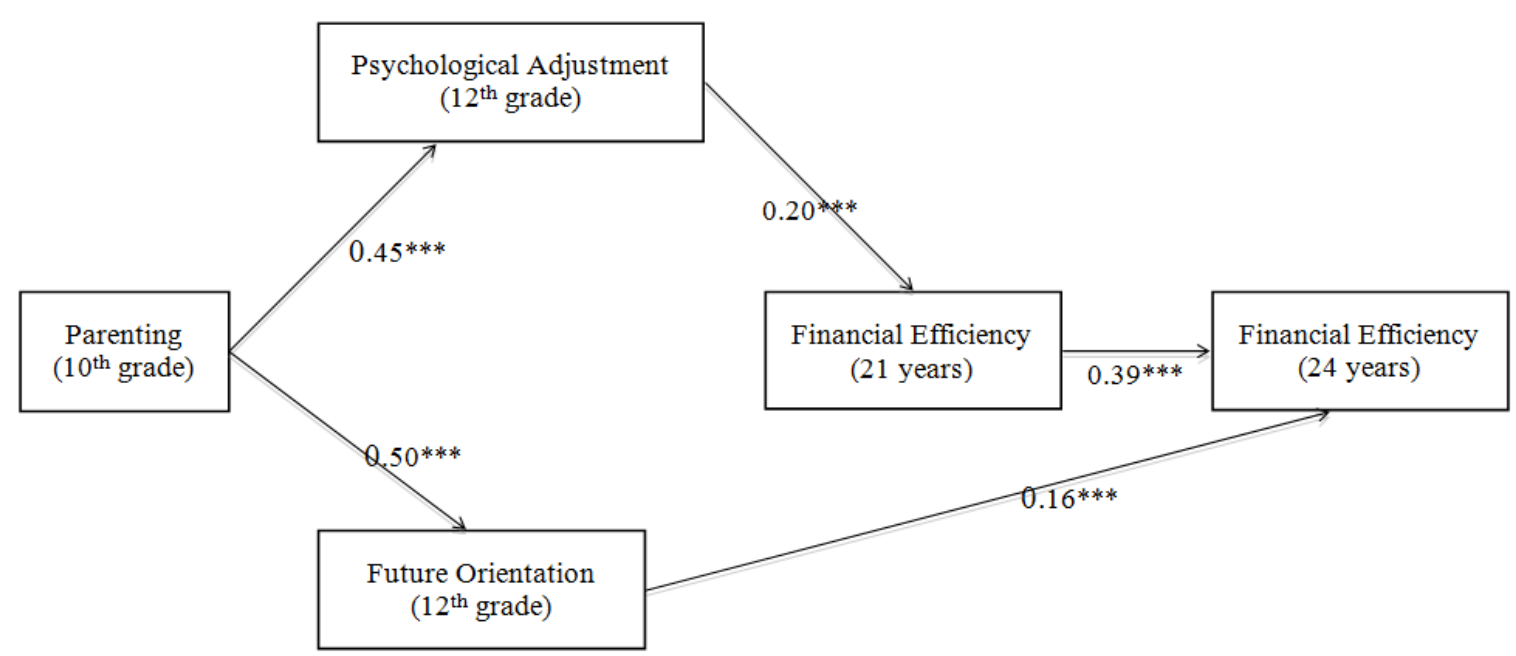

Fig. 2. The pathway of financial efficiency $\chi^{2}=75.5, d f=13$; CFI $=0.946$; IFI $=0.947$; RMSEA $=0.044$ (CI, 0.035-.054); ${ }^{* * *} p<0.001$. The standardized path coefficients are shown. The paths from occupational aspiration to financial efficiency at Wave $7(\beta=0.11, p<0.06)$, from parenting to financial efficiency at Wave $7(\beta=-0.08, n s)$ and Wave $8(\beta=-0.01, n s)$, and from adjustment to financial efficiency at Wave $8(\beta=0.09, n s)$ failed to reach significance. These non significant paths were dropped from the final model

Table 1. Means, Standard Deviations, and Intercorrelations among Study Measures

\begin{tabular}{|c|c|c|c|c|c|c|c|c|}
\hline Variable & 1 & 2 & 3 & 4 & 5 & 6 & 7 & 8 \\
\hline 1. Parental involvement & - & & & & & & & \\
\hline 2. Parental advice & $.52 * * *$ & - & & & & & & \\
\hline 3. Self-esteem & $.18 * * *$ & $.14 * * *$ & - & & & & & \\
\hline 4. Depressive symptoms & $-.15 * * *$ & $-.11 * *$ & $-.43 * * *$ & - & & & & \\
\hline 5. Job identity & $.10^{*}$ & $.16^{* * *}$ & $.20 * * *$ & -.04 & - & & & \\
\hline 6. Occupational expectations & $.18^{* * *}$ & $.21 * * *$ & $.24 * * *$ & $-.19 * * *$ & $.38 * * *$ & - & & \\
\hline 7. Financial efficiency ( 21 years) & $.07^{*}$ & .03 & $.13^{* * *}$ & $-.14 * * *$ & .04 & $.11^{* *}$ & - & \\
\hline 8. Financial efficiency ( 24 years) & $.08 \dagger$ & $.09 *$ & $.10^{* *}$ & $-.16 * * *$ & $.09 *$ & $.16^{* * *}$ & $.40 * * *$ & - \\
\hline$M$ & 5.04 & 4.50 & 4.88 & 3.53 & 5.85 & 6.00 & 5.38 & 5.34 \\
\hline$S D$ & 1.39 & 1.33 & 1.27 & 1.22 & 1.10 & .82 & 1.24 & 1.20 \\
\hline
\end{tabular}

Note: Sample sized ranged from 1053 to $1385 ; \dagger p<0.10 .{ }^{*} p<0.05,{ }^{* *} p<0.01,{ }^{* * *} p<0.001$

\section{Discussion}

According to ASEC (2001), many parents report they are good financial role models and guides for children; however, at the same time, actual behaviors indicate that these self-reports are questionable. Given the lack of studies on parenting behaviors and their effects on children's financial behaviors, the current study attempted to understand the role of parenting behaviors in children's financial efficient behaviors in their later life - young adulthood.

\section{The Pathway of Financial Efficiency}

The present study attempted to enhance understanding of the developmental pathways and processes of financial behaviors among young adults, which will provide directions for future research on this issue. As seen in Fig. 2, findings from the present study showed that earlier parenting behaviors measured by parental advice and involved parenting during adolescence predicted later adolescent children's future oriented attitudes, such as occupational aspirations and job identity. In addition, earlier parenting behaviors significantly predicted positive adolescent adjustment gauged by self-esteem and depression. Although those parenting behaviors did not directly predict financial efficient behaviors in young adulthood, adolescent children's psychosocial adjustment and future oriented attitudes mediated those parenting behaviors and their efficient financial behavior in young adulthood. This can imply that involved parenting and parental talk with their adolescent children for their future plans and concerns positively affect adolescents' better psychosocial adjustment and aspirations in their more specific and detailed occupational plan, which in turn lead to adolescents' more efficient behaviors in managing their finances to pursue their future plans, including success in achieving their future goals.

This pathway of children's financial behaviors is worthy to note in several ways. First, when examining 
parental behaviors and children's consuming behaviors, studies usually examined only parental economic socialization for children, such as teaching saving money (e.g., Bernheim et al., 2001) rather than general parenting behaviors or parent-child relationships. This phenomenon may be due to the uncertain link between general parental behaviors and children's economic behaviors. However, the current study found a potential pathway from parental behaviors to children's financial efficiency and provides better understanding on how broader parenting behaviors, such as parental advice for children's future and involvement (not only parental economic socialization), can shape or influence children's financial behaviors through positive psychosocial adjustment and future orientation. This pathway implies that general parenting behaviors or the quality of parentchild relationships in general is important and critical even for children's financial behaviors. In the future, examination of other potential mediators between parental behaviors and children's financial behaviors could show the importance of general parental behaviors (not limited to teaching behavior regarding finance) and provide a better understanding of the pathway from parental behaviors to children's financial behaviors.

In addition, this pathway provides the long-term effect of parenting behaviors on children's financial behaviors in later life. As addressed in the earlier section, it is hard to find studies using longitudinal data to understand any possible pathway of financial behaviors. Some studies are limited to using concurrent association between parental behaviors and children's economic behaviors (e.g., Clarke et al., 2005; Pinto et al., 2005), other studies examined earlier parenting behaviors and later children's financial behaviors, but they used retrospective data (e.g., Webley and Nyhus, 2006). In addition, even though Nyhus and Webley (2007) examined the association among parental behaviors, including parenting style, children's future orientation and the pattern of spending money, the data was from the same point in time. However, this study provides a better understanding of the long-term effect of parental behaviors using prospective and longitudinal study.

\section{Limitations, Contributions and Directions for Future Research}

Some limitations should be noted when interpreting these findings. First, our sample is largely white, thus these findings may not be generalized to other ethnic groups. For Eastern Asians, such as Chinese and Koreans, parenting is generally known as more 'authoritarian' and/or less communicative and democratic parenting toward children compared to white parents (Wang et al., 2015). Due to their Confucianism cultural background, Eastern Asian parents are, traditionally, less likely to talk with their children over children's issues (Kim et al., 2013). Hence, the measure for parenting behaviors can be differently applied to these different parent groups, which can result in different findings. Second, although the longitudinal study design helps to establish causality, all measures were based on self-reports, which can leave open the possibility of biased information. For example, efficiency of young adults' financial behaviors were measured based on their perception/evaluation. Thus, their actual management of finance can be different from their perception due to their attributes, characteristics and other factors.

Despite those limitations, it is worthwhile to note several contributions of the current study. As addressed above, the current study expanded the existing conceptual model of the association between parenting and children's financial behaviors. First, the conceptual model in the current study did not limit parenting behaviors to financial teachings to children nor modeling their financial behaviors to children as most studies did. The current study examined if developmentally needed parenting behaviors for children (e.g., parental advice for adolescents' future plans for a career or education) were related to children's financial efficacy in later life. Second, the conceptual model in the current study examined the possible mediator between those developmentally needed parenting behaviors and children's efficient financial behaviors - future orientation (i.e., occupational aspiration). By examining adolescents' future orientation as a mediator, how developmentally appropriate parenting behaviors could be related to adolescents' later financial behaviors in young adulthood was explained better. This expanded conceptual model of parenting behaviors and children's financial behaviors in later life could be examined thanks to the prospective and longitudinal data. As addressed above, by using prospective and longitudinal data, the current study could show how parental behaviors in earlier life can influence children's financial behaviors in later life. In addition to expanded conceptual model and longitudinal data, there is another noteworthy contribution of the current study. Even though the sample is predominantly white and from two-parent families, the findings in the current study are based on whole sample including college and non-college youth. Unlike many other studies (e.g., Roberts and Jones, 2001) using a convenient sample from a university setting, this study has balanced the sample between college and non-college youth, which can boost representativeness of youth.

Considering the limitations and contributions addressed above, a few directions for future research can be made. First, as mentioned above, the current study included children from always-married families only mainly in order to prevent any possible impacts of family structure and family process related to changes of family structure (e.g., parental divorce, parental remarriage, loss of nonresidential parent's contact and psychological adjusting those family structures). Indeed, 
Ross and Miller (2009) found that children from divorced families are more likely to report unpredictable finances than their counterparts. Given that parental divorce is negatively related to children's finance/financial behaviors, whereas positive parenting behaviors are related to children's better finance/financial behaviors, parental advice and parental involvement to adolescents may buffer any negative impact of parental divorce on children's efficient financial behaviors. However, to our knowledge there is no research that examines this interaction between parental divorce and parenting behaviors, such as parental advice for children's future and its influence on children's financial behaviors. The examination of this interaction can be a possible area for research in the future.

Another possible direction for future research can be suggesting a conceptual framework that would explain why and how early parenting behaviors and children's financial behaviors are related. Even though the current study suggested a conceptual framework that opencommunication and advice about adolescent children's future concerns are developmentally needed and appropriate parenting behaviors for adolescents, which in turn help them achieve future oriented attitudes that can result in their efficient financial behaviors later, another delicate and insightful conceptual framework explaining the relationship between parenting behaviors and children's financial behaviors later could be beneficial in understanding this association.

Meanwhile, based on the conceptual framework that the current study suggested, another future research direction can be suggested, which is whether how children's locus of control is related to parenting behaviors and their financial behaviors. Locus of control refers to individuals' beliefs about cause and effect in their lives. More to the point, individuals with internal locus of control are more likely to believe they can control their lives since they have skills, abilities and knowledge over events in their lives, whereas individuals with external locus are more likely to believe that their lives are decided/affected by factors that they do not have control over, such as luck, fate and chance. As addressed above, the current study emphasized adolescents' future orientation as a result of positive parenting behaviors as well as a cause of efficient financial behaviors since future orientation is individuals' motivated attitudes for planning for present and future. Given that future oriented attitudes are similar to internal locus of control in a way that individuals try to shape/control their lives based on being active agents for their lives, examining locus of control as a mediator between parenting behaviors and children's financial behaviors seems quite promising for future research that can enhance understanding young adults' financial behaviors. Indeed, Grable et al. (2009) found that individuals with internal locus of control are more likely to have responsible financial management behaviors (e.g., paying bills on time, controlling spending and saving money). In addition, positive parenting behaviors, such as autonomous parenting, assisting children and not overprotecting, are found to be related to children's internal locus of control (e.g., Cohen et al., 2008; Yang and Wang, 2008). Very little, however, is known about the associations among parenting behaviors, children's locus of control and financial behaviors.

In addition, it would be beneficial to examine any possible difference based on the gender of parents and children. Even though many researchers are aware of the potential role of gender of family members in their dynamics, examination of four different dyads of parents and children have not been examined extensively, especially in the dynamics among parental advice, children's future orientation and their financial efficiency. As Steinberg (1990) stated "the four parentadolescent dyads may be characterized by quite different types of relations and may undergo quite different sorts of transformations in adolescence" (p. 226), examination of possible gender roles in this dynamics would be beneficial to understand the role of parental behaviors regarding children's financial behaviors better.

The current study provided a possible first step in understanding the association between parenting behaviors and young adults' financial behaviors with emphasis on children's future orientation. In the future, more advanced and careful examination of other factors (i.e., children's locus of control) with a conceptual framework and longitudinal and prospective data having more representative samples (e.g., college vs. noncollege or always-married vs. divorced families) would provide better understanding of young adults' financial behaviors. Possibly, those research results would shed light on the importance of parenting behaviors in general, not just financial socializing behaviors for children, for making differences in children's efficient financial behaviors, which in turn help educators and/or practitioners in education programs for individuals' finance and/or parenting education set up programs.

\section{Funding Information}

This study was funded by Take Charge America Institute (TCAI). This study used the data of The Michigan Study of Adolescent Life Transitions (MSALT), which has been funded by grants from the National Institute of Mental Health, the National Science Foundation, the National Institute of Child Health and Human Development, the Spencer Foundation and the William T. Grant Foundation.

\section{Conflict of Interest}

The authors declare that they have no conflict of interest. 


\section{Author's Contributions}

Sun-A Lee: Developed the theoretical foundation, wrote, edited, and proofread the manuscript.

Jeong Jin Yu: Analyzed the data and participated in editing the manuscript.

\section{Ethics}

All procedures performed in study involving human participants were in accordance with the ethical standard of the institutional and/or national research committee and with the 1964 Helsinki-declaration and its later amendments or comparable ethical standard.

\section{Informed Consent}

Informed consent was obtained from all individual participants included in the study.

\section{References}

ASEC, 2001. Employee benefit research institute and Mathew Greenwald and associates. Parents, Youth Money Survey, Pension Benefits, 10: 9-10.

Aquilino, W.S., 2006. The nonresidential father-child relationship from adolescence into young adulthood. J. Marriage Family, 68: 929-946. DOI: $10.1111 / \mathrm{j} .1741-3737.2006 .00305 . \mathrm{x}$

Arbuckle, J.L., 2003. AMOS 5.0 [Computer Software]. 1st Edn., Small Waters, Chicago, IL.

Arnett, J.J., 2000. Emerging adulthood: A theory of development from the late teens through the twenties. Am. Psychol., 55: 469-480.

Ashby, J.S., I. Schoon and P. Webley, 2011. Save now, save later? Linkages between saving behavior in adolescence and adulthood. Eur. Psychol., 16: 227-237. DOI: 10.1027/1016-9040/a000067

Bae, S.M., 2016. The influence of emotional difficulty, parent-child relationship, peer relationships, materiallyoriented and appearance-oriented attitudes on adolescent problem behavior. School Psychol. Int., 37: 485-497. DOI: $10.1177 / 0143034316658802$

Baek, E. and G. Hong, 2004. Effects of family life-cycle stages on consumer debts. J. Family Econom., 25: 359-385. DOI: 10.1023/B:JEEI.0000039946.59422.5f

Barber, B.L., 1994. Support and advice from married and divorced fathers: Linkages to adolescent adjustment. Family Relations, 43: 433-438.

Barber, B.L. and J.S. Eccles, 1992. Long-term influence of divorce and single parenting on adolescent family and work-related values, behaviors and aspirations. Psychol. Bull., 111: 108-126.

Bernheim, B.D., D.M. Garrett and D.M. Maki, 2001. Education and saving: The long-term effects of high school financial curriculum mandates. J. Public Econom., 80: 435-465. DOI: $10.1016 / \mathrm{S} 0047-2727(00) 00120-1$
Bradford, W.D., 2003. The saving and credit management of low-income, low-wealth black and white families. Econom. Devel. Quarterly, 17: 53-74.

Carlson, M.J., 2006. Family structure, father involvement and adolescent behavioral outcomes. J. Marriage Family, 68: 137-154.

Caruna, A. and R. Vassallo, 2003. Children's perception of their influence over purchases: The role of parental communication patterns. J. Consumer Marketing, 20: 55-66. DOI: 10.1108/07363760310456955

Cheung, G.W. and R.S. Lau, 2008. Testing mediation and suppression effects of latent variables: Bootstrapping with structural equation models. Organizational Res. Meth., 11: 296-325.

Choi, Y., S. Golder, M.R. Gillmore and D.M. Morrision, 2005. Analysis with missing data in social work research. J. Social Service Res., 31: 23-45.

Clarke, M.C., M.B. Heaton, C.L. Israelsen and D.L. Eggett, 2005. The acquisition of family financial roles and responsibilities. Family Consumer Sci. Res. J., 33: 321-340. DOI: 10.1177/1077727X04274117

Cohen, E., M. Sade, F. Benarroch, Y. Pollak and V. Gross-Tsur, 2008. Locus of control, perceived parenting style and symptoms of anxiety and depression in children with Tourette's syndrome. Eur. Child Adolescent Psychiatry, 17: 299-305.

Cotte, J. and S.L. Wood, 2004. Families and innovative consumer behavior: A triadic analysis of sibling and parental influence. J. Consumer Res., 31: 78-86.

Dew, J., 2008. Debt change and marital satisfaction change in recently married couples. Family Relations, 57: 60-71. DOI: $10.1111 / \mathrm{j} .1741-3729.2007 .00483 . x$

Dubow, E.F., M. Arnett, K. Smith and M.F. Ippolito, 2001. Predictors of future expectations of inner-city children: A 9-month prospective study. J. Early Adolescence, 21: 5-28. DOI: 10.1177/0272431601021001001

Enders, C.K. and D.L. Bandalos, 2001. The relative performance of full information maximum likelihood estimation for missing data in structural equation models. Structural Equation Modeling, 8: 430-457.

Erikson, E.H., 1959. Identity and the life cycle: Selected papers. Psychological, 1: 1-171.

Erikson, E.H., 1968. Identity: Youth and Crisis. 1st Edn., Norton and Co, Oxford, England.

Flouri, E., 1999. An integrated model of consumer materialism: Can economic socialization and maternal values predict materialistic attitudes in adolescents? J. Socio-Econom., 28: 707-724.

Goldberg, S., S. LaCombe, D. Levinson, K.R. Parker and C. Ross et al., 1985. Thinking about the threat of nuclear war: Relevance to mental health. Am. J. Orthopsychiatry, 55: 503-512.

Grable, J.E., J. Park and S. Joo, 2009. Explaining financial management behavior for Koreans living in the United States. J. Consumer Affairs, 43: 80-107. 
Grinstein-Weiss, M., J.S. Spader, Y.H. Yeo, C.C. Key and E.B. Freeze, 2012. Loan performance amonglow-income households: Does prior parental teaching of money management matter? Social Work Res., 36: 257-270.

Gudmunson, C.G. and I.F. Beutler, 2012. Relation of parental caring to conspicuous consumption attitudes in adolescents. J. Family Econom. Issues, 33: 389-399.

Holub, T., 2002. Credit card usage and debt among college and university students. ERIC Clearinghouse Higher Educ.

Jambori, S. and H. Sallay, 2003. Parenting styles, aims, attitudes and future orientation of adolescents and young adults. Rev. Psychol., 10: 131-140.

Jiang, J., Y. Qi-yue, U. Fang, L. Jing and K. Yan-nan, 2015. Mediating of parent-child attachment between family stressors and high school students' materialism. Chinese J. Clin. Psychol., 23: 525-528.

Kasser, T., R.M. Ryan, M. Zax and A.J. Sameroff, 1995. The relations of maternal and social environments to late adolescents' materialistic and prosocial values. Dev. Psychol., 31: 907-914.

Kim, J., J. Latalliade and H. Kim, 2011. Family processes and adolescents' financial behaviors. J. Family Econom. Issues, 32: 668-679.

Kim, S.Y., Y. Wang, D. Orozco-Lapray, Y. Shen and M. Murtuza, 2013. Does “Tiger parenting" exist? Parenting profiles of Chinese Americans and adolescent developmental outcomes. Asian Am. J. Psychol., 4: 7-18.

Kracke, B., 1997. Parental behaviors and adolescents' career exploration. Career Dev. Quarterly, 45: 341-350. DOI: 10.1002/j.2161-0045.1997.tb00538.x

Lee, S.H., S.J. Lennon and N.A. Rudd, 2000. Compulsive consumption tendencies among television shoppers. Family Consumer Sci. Res. J., 28: 463-488. DOI: 10.1177/1077727X00284003

Liu, Z., J. Li, H. Zhu, Z. Cai and L. Wang, 2014. Chinese firms' sustainable development-the role of future orientation, environmental commitment and employee training. Asia Pacific J. Manage., 31: 195-213.

Malmberg, L.E., J. Ehrman and T. Lithen, 2005. Adolescents' and parents' future beliefs. J. Adolescence, 28: 709-723.

Mauro, C.F. and Y.R. Harris, 2000. The influence of maternal child-rearing attitudes and teaching behaviors on preschoolers' delay of gratification. J. Genetic Psychol., 161: 293-308.

Moschis, G.P., 1985. The role of family communication in consumer socialization of children and adolescents. J. Consumer Res., 11: 898-913.

Norvilitis, J.M., 2014. Changes over time in college student credit card attitudes and debt: Evidence from one campus. J. Consumer Affairs, 48: 634-647.
Nurmi, J.E., 1991. How do adolescents see their future? A review of the development of future orientation and planning. Dev. Rev., 11: 1-59. DOI: 10.1016/0273-2297(91)90002-6

Nurmi, J.E. and H. Pulliainen, 1991. The changing parentchild relationship, self-esteem and intelligence as determinants of orientation to the future during early adolescence. J. Adolescence, 14: 35-51.

Nyhus, E.K. and P. Webley, 2007. The relationship between parenting style and adolescents' future orientation and spending preferences. Proc. Nordic Consumer Policy Res. Conf.

Nyhus, E.K. and P. Webley, 2013. The relationship between parenting and the economic orientation and behavior of Norwegian adolescents. J. Genetic Psychol., 174: 620-641.

Olsen, R.A. and C.M. Cox, 2001. The influence of gender on the perception and response to investment risk: The case of professional investors. J. Psychol. Financial Markets, 2: 29-36.

Payne, M.A., 1988. Adolescent fears: Some Caribbean findings. J. Youth Adolescence, 17: 255-266.

Pinto, M.B., D.H. Parente and P.M. Mansfield, 2005. Information learned from socialization agents: Its relationship to credit card use. Family Consumer Sci. Res. J., 33: 357-367.

Preacher, K.J. and A.F. Hayes, 2008. Asymptotic and resampling strategies for assessing and comparing indirect effects in multiple mediator models. Behavior Res. Methods, 40: 879-891.

Pulkkinen, L., 1990. Home atmosphere and adolescent future orientation. Eur. J. Psychol. Educ., 5: 33-43.

Reczek, C., M.B. Thomeer, A., Kissling and H. Liu, 2017. Relationships with parents and adult children's substance use. Addictive Behaviors, 65: 198-206.

Reitman, D. and A.M. Gross, 1997. The relation of maternal child-rearing attitudes to delay of gratification among boys. Child Study J., 27: 279-302.

Robbins, R.B. and A. Bryan, 2004. Relationships between future orientation, impulsive sensation seeking and risk behavior among adjudicated adolescents. J. Adolescent Res., 19: 428-445.

Roberts, J.A. and E. Jones, 2001. Money attitudes, credit card use and compulsive buying among American college students. J. Consumer Affairs, 35: 213-240. DOI: $10.1111 / \mathrm{j} .1745-6606.2001 . t b 00111 . \mathrm{x}$

Ross, L.T. and J.R. Miller, 2009. Parental divorce and college students: The impact of family unpredictability and perception of divorce. J. Divorce Remarriage, 50: 248-259. DOI: $10.1080 / 10502550902790746$

Seginer, R., A. Vermulst and S. Shoyer, 2004. The indirect link between perceived parenting and adolescent future orientation: A multiple-step model. Int. J. Behavioral Dev., 28: 365-378.

Serido, J., S. Shim, A. Mishra and C. Tang, 2010. Financial parenting, financial coping behaviors and well-being of emerging adults. Family Relations, 59: 453-464. DOI: $10.1111 / \mathrm{j} .1741-3729.2010 .00615 . x$ 
Shen, S. and A.G. Sam, 2014. Credit card indebtednedd and psychological well-being over time: Empirical evidence from a household survey. J. Consumer Affairs, 48: 431-456.

Stafford, M., D.L. Kuh, C.R. Gale, G. Mishra and M. Richards, 2016. Parent-child relationships and offspring's positive mental wellbeing from adolescence to early older age. J. Positive Psychol., 11: 326-337. DOI: 10.1080/17439760.2015.1081971

Steinberg, L., 1990. Autonomy, Conflict and Harmony in the Family Relationship. In At the Threshold: The Developing Adolescent, Feldman, S.S. and G.R. Elliot (Eds.), Harvard University Press, Cambridge, MA, pp: 255-176.

Steinberg, L. and J.S. Silk, 2002. Parenting Adolescents. In: Handbook of Parenting, Bronstein, M.C. (Ed.), Mahwah, NJ: Earlbaum, pp: 103-133.

Stones, B. and R.V. Maury, 2006. Indicators of personal financial debt using a multi-disciplinary behavioral model. J. Econom. Psychol., 27: 543-556. DOI: 10.1016/j.joep.2005.11.002

Tomarken, A.J. and N.G. Waller, 2005. Structural equation modeling: Strengths, limitations and misconceptions. Ann. Rev. Clin. Psychol., 1: 31-65. PMID: 17716081
Tucker, C.J., B.L. Barber and J.S. Eccles, 2001. Advice about life plans from mothers, fathers and siblings in always-married and divorced families during late adolescence. J. Youth Adolescence, 30: 729-747. DOI: $10.1023 / \mathrm{A}: 1012233712862$

Wang, Y.C., H.Y. Chan, C.W. Lin and J.R. Li, 2015. Association of parental warmth and harsh discipline with developmental trajectories of depressive symptoms among adolescents in Chinese society. J. Family Psychol., 29: 895-906.

Webley, P. and E.K. Nyhus, 2001. Life-cycle and dispositional routes into problem debt. British $\mathrm{J}$. Psychol., 92: 423-446. DOI: $10.1348 / 000712601162275$

Webley, P. and E.K. Nyhus, 2006. Parents' influence on children's future orientation and saving. J. Econom. Psychol., 27: 410-164. DOI: $10.1016 /$ j.joep.2005.06.016

Wood, D. and D. Middleton, 1975. A study of assisted problem-solving. British J. Psychol., 66: 181-191. DOI: $10.1111 /$ j.2044-8295.1975.tb01454.x

Yang, Z. and Z. Wang, 2008. Correlation of the locus of control and parental rearing patterns of the junior high school students. Chinese J. Clin. Psychol., 16: 401-402. 